\title{
Common Data Elements for Concussion in Tertiary Care: Phase One in Ontario
}

\author{
Cindy Hunt, Alicja Michalak, Donna Ouchterlony, Shawn Marshall, \\ Cheryl Masanic, Chantal Vaidyanath, Shree Bhalerao, Michael D. Cusimano, \\ Deanna Quon, Lisa K. Fischer, Andrew Baker
}

\begin{abstract}
Background: Standardized data collection for traumatic brain injury (TBI) (including concussion) using common data elements (CDEs) has strengthened clinical care and research capacity in the United States and Europe. Currently, Ontario healthcare providers do not collect uniform data on adult patients diagnosed with concussion. Objective: The Ontario Concussion Care Strategy (OCCS) is a collaborative network of multidisciplinary healthcare providers, brain injury advocacy groups, patient representatives, and researchers with a shared vision to improve concussion care across the province, starting with the collection of standardized data. Methods: The International Framework of Functioning Disability and Health was selected as the conceptual framework to inform the selection of CDEs. The CDEs recommended by the OCCS were identified using key literature, including the National Institute of Neurological Disorders and Stroke-Zurich Consensus Statements for concussion in sport and the Ontario Neurotrauma Foundation Concussion/mTBI clinical guidelines. Results: The OCCS has recommended and piloted CDEs for Ontario that are readily available at no cost, clinically relevant, patient friendly, easy to interpret, and recognized by the international scientific community. Conclusions: The implementation of CDEs can help to shift Ontario toward internationally recognized standard data collection, and in so doing yield a more comprehensive evidence-based approach to care while also supporting rigorous research.
\end{abstract}

RÉSUMÉ: Éléments de données communs concernant le traitement des commotions cérébrales dans les centres de soins tertiaires : la première phase en Ontario. Contexte: En utilisant des éléments de données communs (common data elements), la collecte normalisée de données au sujet des lésions cérébrales traumatiques (LCT), ce qui inclut les commotions cérébrales, a pu renforcer les soins cliniques et les capacités de la recherche aux États-Unis et en Europe. Au moment où l'on se parle, les fournisseurs ontariens de soins de santé ne collectent pas de données uniformes en ce qui concerne les patients adultes chez qui on a diagnostiqué une commotion cérébrale. Objectifs: La Ontario Concussion Care Strategy (OCCS) est un réseau coopératif qui rassemble des fournisseurs multidisciplinaires de soins de santé, des groupes de défense des personnes ayant subi des lésions, des représentants des patients et des chercheurs qui partagent une vision commune quant à la nécessité d'améliorer, partout dans la province, les soins prodigués à la suite d'une commotion cérébrale. Cela commence, selon eux, par une collecte normalisée de données. Méthodes: Nous avons choisi la Classification internationale du fonctionnement, du handicap et de la santé (CIF) à titre de cadre conceptuel sur lequel devait reposer la collecte de nos éléments de données communs. La OCCS a recommandé ces éléments en s'appuyant sur des publications clés, par exemple celles du National Institute of Neurological Disorders and Stroke, sur les énoncés du consensus de Zurich au sujet des commotions cérébrales dans le sport et sur les lignes directrices de pratique clinique de la Fondation ontarienne de neurotraumatologie au sujet des commotions cérébrales et des LCT légères. Résultats: La OCCS a recommandé des éléments de données communs et piloté leur collecte en Ontario. Ces éléments sont gratuits et facilement accessibles, pertinents sur le plan clinique, avantageux pour les patients, faciles à interpréter et reconnus par la communauté scientifique internationale. Conclusions: La mise en œuvre d'une collecte d'éléments de données communs peut ainsi aider l'Ontario à effectuer un virage vers des méthodes normalisées de collecte de données reconnues à l'échelle internationale et, ce faisant, à offrir des soins fondés sur des données probantes tout en encourageant des travaux de recherche rigoureux.

Keywords: Brain injury, Traumatic, Epidemiology

doi:10.1017/cjn.2017.222

Can J Neurol Sci. 2017; 44: 676-683

From the Head Injury Clinic, Trauma and Neurosurgery Program, St. Michael's Hospital, University of Toronto, Toronto, Ontario, Canada (CH, AM, DO, CM, CV, SB); Dalla Lana School of Publc Health, University of Toronto, Toronto, Ontario, Canaa (CH); Traumatic Brain Injury Rehabilitation, Ottawa Hospital Research Institute, The Ottawa Hospital, Ottawa, Ontario, Canada (SM); Department of Medicine, University of Ottawa, Ottawa, Ontario, Canada (SM, DQ); University Health Network, Toronto Rehabilitation Clinic, Toronto, Ontario, Canada (CM, CV); Department of Surgery, Division of Neurosurgery, Injury Prevention Research Office, Keenan Research Centre, St. Michael's Hospital, University of Toronto, Toronto, Ontario, Canada (MDC); Physical Medicine and Rehabilitation, Ottawa Hospital, Ottawa, Ontario, Canada (DQ); Department of Family Medicine, Schulich School of Medicine and Dentistry, University of Western Ontario, London, Ontario, Canada (LKF); Faculty of Health Sciences/Kinesiology, Western University, London, Ontario, Canada (LKF); Sport and Exercise Medicine, Fowler Kennedy Sport Medicine Clinic, Western University, London, Ontario, Canada (LKF); Departments of Anaesthesia and Critical Care, Keenan Research Centre for Biomedical Science, St. Michael's Hospital, University of Toronto, Toronto, Ontario, Canada (AB).

Received November 22, 2016. Final Revisions Submitted May 15, 2017. Date of Acceptance June 1, 2017.

Correspondence to: Cindy Hunt, Senior Research Associate, Head Injury Clinic, Trauma and Neurosurgery Program, St. Michael's Hospital, and Assistant Professor, Dalla Lana School of Public Health, Health Sciences Building, 155 College Street, 6th Floor, University of Toronto, Toronto, Ontario ON M5T 3M7, Canada. Email: huntci@ smh.ca. 


\section{INTRODUCTION}

Concussion/mild traumatic brain injury is a worldwide public health problem and accounts for the largest group of brain injuries. ${ }^{1-5}$ Using common data elements (CDEs) to characterize concussion is the most important strategy to begin to address this global burden. ${ }^{2}$ The implementation of CDEs for concussion can increase the efficiency and effectiveness of clinical treatment, clinical research studies, and data quality, as well as facilitate data sharing and educate new clinical investigators. ${ }^{4}$ Improving concussion surveillance through collection of CDEs is essential to determining whether progress is being made to reduce the burden of concussion on public health. ${ }^{6}$ In spite of this convincing evidence, healthcare providers (HCPs) across Ontario do not collect uniform CDEs on concussion.

One-fifth of adults with concussion experience persisting symptoms (PSs), defined as lasting beyond 3 months of the traumatic event. ${ }^{1}$ These may include such symptoms as cognitive impairments, headache, sleep disturbance, disorders of balance, fatigue, dizziness, mood disorders, and depression. ${ }^{7}$ Patients in Ontario with PSs may be referred to tertiary care (TC) and wait an average of 7 months to be seen in Ontario. ${ }^{8}$ During this wait time, it has been estimated that Ontario could be spending up to $\$ 110$ million annually, as patients are seeking symptom relief from a diverse range of services, while they wait for TC. ${ }^{9}$ There are currently numerous and diverse concussion care providers across the province. ${ }^{10}$ Consistent patient assessment measures for PSs are not widely used in spite of the recommendations of clinical guidelines. As a result, there is a pattern of haphazard collection of information. Patients with PSs are followed over time, but without consistent outcomes measures it is difficult to share information from one clinician to another to ensure continuity of care. For example, using different tools to monitor symptoms precludes the ability to observe patterns and responses to symptom management. Early implementation of CDEs in Ontario could facilitate a streamlined systematic approach to care, improve access to care, help decrease specialty care wait times, reduce patient suffering, and reduce the economic impact of concussion. The Ontario Concussion Care Strategy (OCCS) has successfully established a collaborative network to promote and implement CDEs. The OCCS has recommended and implemented CDEs for TC. The CDEs selected are readily available at no cost, clinically relevant, patient-friendly, easy to interpret, and recognized by the international scientific community. The purposes of the present paper are to: (1) describe the OCCS's vision for CDEs; (2) interpret the theoretical framework used to recommend CDEs for TC; (3) define the key steps by OCCS to implement CDEs; and (4) consider the strengths and limitations of CDEs in concussion care.

\section{Ontario Concussion Care Strategy (OCCS)}

The OCCS consists of a group of multidisciplinary HCPs (physiotherapy, occupational therapy, nursing, physiatry, psychiatry, family, and emergency clinicians) with experience in caring for patients with concussion and collaborating with brain injury advocate groups, patient representatives, and researchers. Participants in the OCCS are from across the province of Ontario: Ottawa, Kingston, Sudbury, Thunder Bay, Toronto, Hamilton, and London. Over 40 participants attended the inaugural meeting in April of 2014, initiated by the St. Michael's Hospital Head Injury Clinic. The OCCS operates under a model of shared leadership. Members of the
OCCS share a common vision, which is to improve concussion care across Ontario and reduce the impact of chronic impairment from concussion. The OCCS identified the first phase of the strategy to achieve this vision as being the implementation of CDEs in TC.

\section{Methods}

\section{The International Classification of Functioning Disability and Health Framework}

The practice of patient-centred interprofessional care was considered when choosing a theoretical framework for standardized data collection in concussion care. The World Health Organization's International Classification of Functioning, Disability, and Health $(\mathrm{ICF})^{16}$ provided a comprehensive, multidisciplinary, bio-psychosocial model of functioning and disability, and has been previously used to describe neurological trauma in both acute and chronic phases. ${ }^{17,18}$ The value of the ICF in interprofessional practice and research has gained international recognition. It has demonstrated strengths in the promotion of a comprehensive perspective on health, ease in the application of this theory to practice, and the ability to enhance communication and collaboration across HCPs. ${ }^{19}$ The ICF has been a catalyst for interprofessional education and collaborative practice in other neurological health conditions. ${ }^{20}$ Table 1 describes the four domains of the ICF framework and the corresponding recommended CDEs for Ontario TC within each domain. Table 1 also outlines the definition and rationale, and references the source of the CDE.

The four domains of the ICF framework were used as "building blocks" in the selection of CDEs recommended by the OCCS. The first domain encompasses "body functions and structure," which specifies the physiological functions of body systems and impairments in body function. In the recommendation of CDEs, the OCCS divided this domain into pre-injury, periinjury and post-injury body function and structure, to align with parts of the classic injury grid designed by Haddon. ${ }^{21}$ The second domain, "activities," comprises various activities involved in daily life. The OCCS modified this domain to include characteristics about the person's activities at the time of the injury, such as date/time of injury and mechanism of injury. The third domain is "participation," which refers to the nature and extent of the person's societal functioning. Several examples of CDEs in this domain include marital status, persons living with, employment, and education. Contextual factors comprise the fourth domain. This domain is further divided into "personal factors" (internal influences of functioning), with examples of CDEs including immigration status, ethnicity, alcohol, and drug use, and "environmental factors" (or external influences on functioning), with examples of CDEs in this domain being protective equipment and type of housing.

\section{Key STEPS by OCCS to IMPLEMENT CDEs}

The steps in the identification and implementation of CDEs are outlined in Figure 1. First, an environmental scan was conducted with five TC centres in the OCCS. Mapping of patient measures collected at each site revealed limited commonalities across sites. This was a further call to action for the collection of standardized data. Secondly, a CDE subcommittee was established by the OCCS. The subcommittee began reviewing landmark documents 
Table 1: Ontario concussion care strategy recommended common data elements for tertiary care

\begin{tabular}{|c|c|c|c|}
\hline ICF Domain and CDE & CDE definition & Rationale and scoring & References \\
\hline \multicolumn{4}{|l|}{$\begin{array}{l}\text { 1. Body function \& } \\
\text { structure (pre-injury) }\end{array}$} \\
\hline Personal health history & Past illness diagnosed by a clinician & $\begin{array}{l}\text { History of headaches, learning disability, mental health, and other } \\
\text { health conditions }\end{array}$ & 7,14 \\
\hline Suicidality & Suicide attempts in year prior to injury & & 14 \\
\hline Family health history & Past illness to immediate family diagnosed by a clinician & Family history of above may increase risk of PSs & 7,14 \\
\hline $\begin{array}{l}\text { Weight, height, gender, } \\
\text { handedness }\end{array}$ & $\begin{array}{l}\text { Weight and height before injury } \\
\text { Hand of preference }\end{array}$ & Calculate BMI at time of injury and follow-up & 7,14 \\
\hline $\begin{array}{l}\text { Adverse Childhood } \\
\text { Experiences } \\
\text { Questionnaire } \\
\end{array}$ & $\begin{array}{l}\text { The CDC's Adverse Childhood Experiences Study uncovered a } \\
\text { link between childhood trauma and chronic diseases people } \\
\text { develop as adults, as well as social and emotional problems. }\end{array}$ & $\begin{array}{l}\text { One point for each type of trauma. The higher your ACE score, } \\
\text { the higher your risk of health and social problems. ACE }>4 \text { is } \\
\text { considered serious. }\end{array}$ & $\begin{array}{l}\text { NEW-OCCS, } \\
22\end{array}$ \\
\hline Physical activity & $\begin{array}{l}\text { Did you participate in sports? Yes, No } \\
\text { If yes, what level did you play? (recreational, competitive, elite, } \\
\text { professional) } \\
\text { Did you exercise at least } 30 \text { minutes or more each day for } \\
5 \text { days per week or more? Yes, No }\end{array}$ & May be a risk and/or protective factor & NEW-OCCS \\
\hline $\begin{array}{l}\text { Ohio State University } \\
\text { TBI Identification } \\
\text { Methods-Short Form }\end{array}$ & $\begin{array}{l}\text { Designed to use self- or proxy reports to elicit summary indices } \\
\text { reflecting TBIs occurring over a person's lifetime. While self-report } \\
\text { is not an ideal for determining how much compromise a person's } \\
\text { brain may have incurred as a result of lifetime exposure to TBI, it is } \\
\text { for now the gold standard for both research and clinical uses. }\end{array}$ & $\begin{array}{l}\text { Nominal and ordinal variables with six total scores: } \\
\text { \#TBI-LOC, \#TBI-LOC > } 30 \text { minutes, age at first TBI-LOC, } \\
\text { worst injury, \#anoxic injuries }\end{array}$ & $7,14,23$ \\
\hline \multicolumn{4}{|l|}{ (Post-Injury) } \\
\hline Seizure & $\begin{array}{l}\text { Within } 48 \text { hours post-injury (immediate seizures and/or } \\
\text { delayed seizures) }\end{array}$ & May suggests injury severity & 7,14 \\
\hline Vomiting & Within 48 hours post-injury & Ibid. & 7,14 \\
\hline Amnesia before injury & $\begin{array}{l}\text { Memory loss before the injury such that patient is unable to } \\
\text { recount events prior to injury }\end{array}$ & Ibid. & 7,14 \\
\hline Amnesia after injury & $\begin{array}{l}\text { Memory loss after injury, such that patient is unable to recount } \\
\text { events post-injury }\end{array}$ & Ibid. & 7,14 \\
\hline Loss of consciousness & Includes duration and if a witness present & Ibid. & 7,14 \\
\hline $\begin{array}{l}\text { Alteration of } \\
\text { consciousness }\end{array}$ & Feeling dazed or confused & Ibid. & 7,14 \\
\hline Current medications & $\begin{array}{l}\text { Current medications for other health-related issues as well as for } \\
\text { concussion, including vitamins and over-the-counter } \\
\text { medication. }\end{array}$ & $\begin{array}{l}\text { Impact of polypharmacy needs assessment. Effectiveness of } \\
\text { medications used for concussion symptom relief requires } \\
\text { assessment. }\end{array}$ & 7,14 \\
\hline Numeric pain scale & $\begin{array}{l}\text { This standardized scale asks the person in pain to assign a number, } \\
\text { from } 0 \text { to } 10 \text {, to the severity of their pain. }\end{array}$ & $\begin{array}{l}\text { The values on the pain scale correspond to pain levels: } \\
1-3=\text { mild pain } \\
4-6=\text { moderate pain } \\
7-10=\text { severe pain }\end{array}$ & $\begin{array}{l}\text { NEW- } \\
\text { OCCS, } 24\end{array}$ \\
\hline $\begin{array}{l}\text { Montreal Cognitive } \\
\text { Assessment Score }\end{array}$ & $\begin{array}{l}\text { To assess for mild cognitive impairment. Each of the cognitive } \\
\text { domains can be affected by mild TBI. It assesses several } \\
\text { cognitive domains: attention and concentration, conceptual } \\
\text { thinking, calculations, orientation, executive functions, visual } \\
\text { constructional skills, memory, and language. }\end{array}$ & $\begin{array}{l}\text { Score }<26 \text { suggests mild cognitive impairment } \\
\text { Group norms established and available on website for normal } \\
\text { controls, mild cognitive impairment, and Alzheimer's disease }\end{array}$ & 7,25 \\
\hline $\begin{array}{l}\text { Rivermead Post- } \\
\text { Concussion Symptoms } \\
\text { Questionnaire }\end{array}$ & $\begin{array}{l}\text { Compares before injury and captures the symptoms experienced } \\
\text { over the past } 24 \text { hours }\end{array}$ & $\begin{array}{l}\text { A 5-point Likert-type scale with interval variables that can result in a } \\
\text { total score from } 0 \text { to } 64 \text {. Responses include: } 0 \text { (not experienced at } \\
\text { all ), } 1 \text { (no more of a problem than before the injury), } 2 \text { ( mild } \\
\text { problem), } 3 \text { (moderate problem), } 4 \text { (severe problem). } \\
\text { The items are scored in two groups. The first group (RPQ-3) } \\
\text { consists of the first three items (headaches, feelings of dizziness, } \\
\text { and nausea), and the second group (RPQ-13) comprises the next } \\
13 \text { items. The total score for RPQ-3 items is potentially } 0-12 \text { and } \\
\text { is associated with early symptom clusters of post-concussive } \\
\text { symptoms. If there is a higher score on the RPQ-3, earlier } \\
\text { reassessment and closer monitoring is recommended. } \\
\text { The RPQ-13 score is potentially 0-52, where higher scores reflect } \\
\text { greater severity of post-concussive symptoms. The RPQ-13 items } \\
\text { are associated with a later cluster of symptoms. The later cluster of } \\
\text { symptoms is associated with having a greater impact on } \\
\text { participation, psychosocial functioning, and lifestyle. } \\
\text { Of note, neck pain has been added to the bottom of the Rivermead } \\
\text { as an option for patient self-reporting. }\end{array}$ & $7,14,26$ \\
\hline
\end{tabular}


Table 1. Continued

\begin{tabular}{|c|c|c|c|}
\hline ICF Domain and CDE & CDE definition & Rationale and scoring & References \\
\hline $\begin{array}{l}\text { Sleep and Concussion } \\
\text { Questionnaire }\end{array}$ & $\begin{array}{l}\text { Questionnaire to assess changes in sleep quality following a } \\
\text { concussion }\end{array}$ & $\begin{array}{l}\text { Add scores for all } 10 \text { items; total score ranges from } 0 \text { to } 31 \text {. } \\
\text { Score } 0-7=\text { no clinically significant change (no action required } \\
\text { UNLESS there is a preexisting sleep problem that has not been } \\
\text { addressed, as this can exacerbate concussion symptoms and } \\
\text { slow down recovery). } \\
\text { Score } 8-15=\text { subclinical change (requires monitoring). Reassure } \\
\text { individual that complete resolution anticipated with resolution } \\
\text { of concussion symptoms). } \\
\text { Score } 16-22=\text { clinical changes of moderate severity (further } \\
\text { assessment of precipitating factors recommended and possible } \\
\text { intervention required). } \\
\text { Score } 23-31=\text { clinically severe changes in sleep or wakefulness } \\
\text { (further assessment of precipitating factors, referral to specialist } \\
\text { may be indicated and intervention may be indicated). }\end{array}$ & 7,27 \\
\hline $\begin{array}{l}\text { Generalized Anxiety } \\
\text { Disorder 7-Item Scale }\end{array}$ & This tool can assess anxiety severity in diverse clinical settings & $\begin{array}{l}\text { Anxiety severity is calculated by assigning scores of } 0,1,2 \text {, and } 3 \\
\text { to the response categories of "not at all," "several days," "more } \\
\text { than half the days," and "nearly every day," respectively. The } \\
\text { GAD-7 total score for the seven items ranges from } 0 \text { to } 21 \text {. } \\
\text { Scores of } 5,10 \text {, and } 15 \text { represent cut-points for mild, moderate, } \\
\text { and severe anxiety, respectively. Score interpretation: } 0- \\
4=\text { normal, } 5-9=\text { mild anxiety, } 10-14=\text { moderate anxiety, } \\
15-21=\text { severe anxiety. } \\
\text { A score of } 10 \text { or greater is the recommended cut-point for } \\
\text { identifying cases in which a formal diagnosis of GAD may be } \\
\text { considered. Elevated GAD-7 scores also raise the possibility } \\
\text { that one or more of the other most common anxiety disorders } \\
\text { may be present (e.g., panic disorder, PTSD, and social phobia). }\end{array}$ & 7,28 \\
\hline PHQ-9 & $\begin{array}{l}\text { Patient to reflect and respond how often they have been bothered } \\
\text { by symptoms of depression }\end{array}$ & $\begin{array}{l}\text { 4-point Likert-type scale with interval variables with responses } \\
\text { that include: } 0 \text { (not at all), } 1 \text { (several days), } 2 \text { (more than half the } \\
\text { days), } 3 \text { (nearly every day). Total scores of } 0-5=\text { mild, } \\
6-10=\text { moderate, } 11-15=\text { moderately severe, } 16-20=\text { severe } \\
\text { depression. General population and has been validated with } \\
\text { TBI patients. PHQ- } 9>12 \text { suggestive of depressive disorder. }\end{array}$ & $7,14,29$ \\
\hline Headache questionnaire & & Not a validated scale & NEW-OCCS \\
\hline $\begin{array}{l}\text { Barrow Neurological } \\
\text { Institute (BNI) } \\
\text { Fatigue Scale }\end{array}$ & Brief tool used in concussion patients to access fatigue & Scales on rating from 0 to 7 & 7,30 \\
\hline $\begin{array}{l}\text { Associated injuries at } \\
\text { time of concussion }\end{array}$ & Other injuries & May provide indication of PTSD & 7,14 \\
\hline $\begin{array}{l}\text { Health service } \\
\text { utilization }\end{array}$ & $\begin{array}{l}\text { Please indicate the number of times you have visited the following } \\
\text { health services to support you with your most recent head } \\
\text { injury or concussion. Response options include: emergency } \\
\text { department, family doctor, walk-in clinic, psychiatrist, } \\
\text { neurologist, psychologist, rehab (physiotherapy, OT, social } \\
\text { worker), alternative therapies (chiropractor, acupuncturist, } \\
\text { osteopath, naturopath), other (specify). }\end{array}$ & $\begin{array}{l}\text { Increased shopping around for health services; may be high-cost } \\
\text { and may be experiencing low satisfaction with symptom relief } \\
\text { and management strategies. }\end{array}$ & NEW-OCCS \\
\hline \multicolumn{4}{|l|}{$\begin{array}{l}\text { 2. Activity at time of } \\
\text { injury }\end{array}$} \\
\hline Date, time & Date and time are commonly collected in injury data & $\begin{array}{l}\text { Helps identify causative factors and patterns (i.e., seasonal risks } \\
\text { and/or day versus nighttime injury) to build prevention policies }\end{array}$ & 7,14 \\
\hline Place & Location of injury & Ibid. & 7,14 \\
\hline Type of activity & $\begin{array}{l}\text { Transportation-related, falls, flying/falling objects, violence- } \\
\text { related, and/or sport/exercise }\end{array}$ & Indicative of injury severity & \\
\hline Mechanism of injury & Mechanical forces at time of injury & Ibid. & 7,14 \\
\hline Glasgow Coma Scale & Brain injury severity & Ibid. & 7,14 \\
\hline CT scan at time of injury & Including results & Ibid. & 7,14 \\
\hline $\begin{array}{l}\text { Immediate health } \\
\text { services }\end{array}$ & Who attended to injury, if anyone & Ibid. & 14 \\
\hline Litigation & Clinician may or may not chose to ask & May play a role & NEW-OCCS \\
\hline \multicolumn{4}{|l|}{ 3.Participation } \\
\hline Marital status & Pre- and post-injury marital status is reported & Changes in levels of social support & 7,14 \\
\hline Persons living with & Number and ages of children pre- and post-injury reported & Level of stress & 14 \\
\hline
\end{tabular}


Table 1. Continued

\begin{tabular}{|c|c|c|c|}
\hline ICF Domain and CDE & CDE definition & Rationale and scoring & References \\
\hline Education & Highest level of education & Knowledge translation & 7,14 \\
\hline Employment & Pre- and post-injury occupation & Return to function & 7,14 \\
\hline Duration of employment & $\begin{array}{l}\text { The year before injury; average number of hours worked and } \\
\text { number of weeks employed }\end{array}$ & Return to function, quality of life & 14 \\
\hline $\begin{array}{l}\text { Primary employer post- } \\
\text { injury }\end{array}$ & $\begin{array}{l}\text { If working post-injury, is the current employer same as before } \\
\text { injury }\end{array}$ & Ibid. & 14 \\
\hline $\begin{array}{l}\text { Return to competitive } \\
\text { work }\end{array}$ & Return to work and time returned to work & Ibid. & 14 \\
\hline Income & Annual earnings reported pre- and post-injury & $\begin{array}{l}\text { Access to specialized services may be in jeopardy if limited } \\
\text { income and no or limited insurance coverage. }\end{array}$ & 14 \\
\hline Convicted crime & Ever in jail for or convicted of a crime? & Support may be compromised & 14 \\
\hline $\begin{array}{l}\text { Community } \\
\text { engagement: } \\
\text { Participant } \\
\text { Assessment with } \\
\text { Recombined } \\
\text { Tools-Objective }\end{array}$ & $\begin{array}{l}\text { An objective measure of community participation, representing } \\
\text { functioning at the societal level. Developed by the NIDRR- } \\
\text { sponsored Traumatic Brain Injury Model Systems. }\end{array}$ & $\begin{array}{l}\text { All items are scored on a } 0 \text {-to- } 5 \text { scale, and domain scores are the } \\
\text { average of items in the domain. Domains include productivity, } \\
\text { social relations, and out and about. Lower scores may indicate } \\
\text { lack of community engagement. Pre- and post-injury measures } \\
\text { are obtained. }\end{array}$ & 14,31 \\
\hline $\begin{array}{l}\text { Quality of Life, } \\
\text { QOLIBRI-OS }\end{array}$ & $\begin{array}{l}\text { Self-reported health-related quality of life screening tool } \\
\text { developed for patients with TBI }\end{array}$ & $\begin{array}{l}\text { Six-item tool reduced from } 37 \text {-item QOLIBRI. Responses are } \\
\text { made on a 5-point scale from "not at all" to "very" and assigned } \\
\text { values } 1 \text { to } 5 \text {. It is calculated by computing the mean for the six } \\
\text { items provided no more than two responses are missing. } \\
\text { Converting this to a percentage score by subtracting } 1 \text { and then } \\
\text { multiplying by } 25 \text {. QOLIBRI-OS scores range from } 1 \text { to } 100 \text {. }\end{array}$ & 14,32 \\
\hline \multicolumn{4}{|l|}{ 4. Environmental factors } \\
\hline $\begin{array}{l}\text { Protective equipment at } \\
\text { time of injury }\end{array}$ & Type and if used & $\begin{array}{l}\text { Provides insight into impact of injury and patient safety } \\
\text { awareness and/or conduct }\end{array}$ & 14 \\
\hline PTSD screen & $\begin{array}{l}\text { The PC-PTSD is a 4-item screen that was designed for use in } \\
\text { primary care and other medical settings and is currently used to } \\
\text { screen for PTSD. The screen includes an introductory sentence } \\
\text { to cue respondents to traumatic events. The screen does not } \\
\text { include a list of potentially traumatic events. }\end{array}$ & $\begin{array}{l}\text { Current research suggests that the results of the PC-PTSD should } \\
\text { be considered "positive" if a patient answers "yes" to any three } \\
\text { items. Those screening positive should then be assessed with a } \\
\text { structured interview for PTSD. }\end{array}$ & $7,14,33$ \\
\hline Type of housing & Housing type pre- and post-injury & May contribute to stress combined with persons living with & 14 \\
\hline \multicolumn{4}{|l|}{ 5. Personal factors } \\
\hline Immigration & $\begin{array}{l}\text { Born in Canada or immigrant less than } 5 \text { years or more than } 5 \\
\text { years }\end{array}$ & Newer immigrant may have few supports and resources & 14 \\
\hline Ethnicity & $\begin{array}{l}\text { Selection of ethnic background; person may select multiple } \\
\text { backgrounds }\end{array}$ & $\begin{array}{l}\text { May be an indicator of social supports and resources and their } \\
\text { perspective on injury }\end{array}$ & 14 \\
\hline Language & $\begin{array}{l}\text { Selection of language spoken; person may select multiple } \\
\text { backgrounds }\end{array}$ & $\begin{array}{l}\text { Non-English-speaking persons may have challenges with } \\
\text { resource material for symptoms management }\end{array}$ & 14 \\
\hline Tobacco & Pre- and post-injury smoking tobacco behaviour & Substance use & 7,14 \\
\hline Drugs & Pre- and post-injury use of illicit or non-prescription drugs & Ibid. & 7,14 \\
\hline Alcohol & Pre- and post-injury use of alcohol & Ibid. & 7,14 \\
\hline
\end{tabular}

Shading indicates new experimental CDE initiated by OCCS.

on concussion care from provincial and international healthcare jurisdictions (Unites States and Europe). A brief description of the landmark documents is offered below.

1. The Ontario Neurotrauma Foundation (ONF) Guidelines for Concussion/mTBI and Persistent Symptoms. ${ }^{7}$ Released in 2008 and revised in 2013, these guidelines are written for HCPs implementing evidence-based care for adults with persistent postconcussive symptoms. A comprehensive literature review was undertaken in the development of these guidelines.

2. The National Institute of Neurological Disorder and StrokeCommon Data Elements. ${ }^{14}$ This initiative was begun in 2007 by international clinical experts building consensus for standardized data acquisition in traumatic brain injury. CDEs became actionable information by enabling comparison across studies.

3. The Zurich Consensus Statement on Concussion in Sport. ${ }^{15}$ Developed by an international panel of sports concussion experts for use by HCPs involved in the care of injured athletes to further inform the treatment and management of sports-related concussion.

Four guiding principles were agreed upon in selecting CDEs. These principles included: (1) CDEs will enhance the standard of practice by selecting clinically relevant measures; (2) CDEs will be dynamic and evolve over time; (3) resources will be needed to review and revise CDEs on a semiannual basis; and (4) CDEs need to be readily available at no cost, easy to implement, easy to 


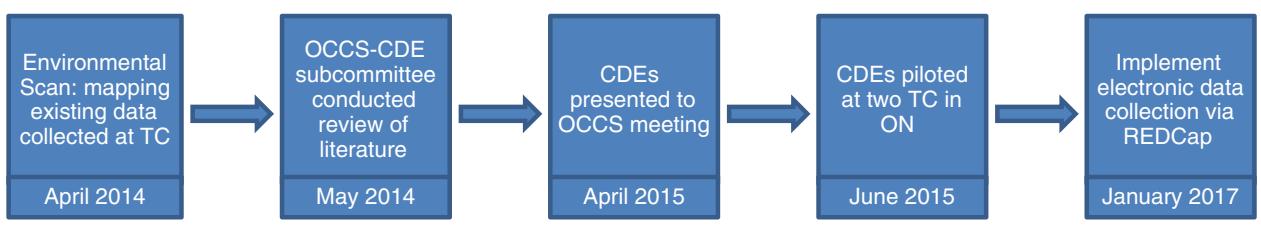

Figure 1: Steps to identification and implementation of CDEs for concussions in Ontario.

collect, and easy to interpret. The subcommittee presented their recommended CDEs to the larger OCCS group. The CDEs were discussed and accepted at a face-to-face meeting in April of 2015. The OCCS CDE subcommittee developed a patient self-reported "baseline patient questionnaire." This questionnaire embeds the CDEs in a series of questions and standardized screening tools for the patient to complete. Two weeks in advance of the TC clinic appointment, the patient receives the questionnaire by mail, giving them ample time to complete and bring it to their TC appointment. Patients require 20 to 45 minutes to complete the questionnaire. A "significant other" can assist if necessary. Upon subsequent visits to the TC clinic (if required), the OCCS recommends selected CDEs to be repeated in a "self-reported follow-up questionnaire." CDEs in the follow-up TC questionnaire include repeated measures of symptoms and functional independence (return to work/school and/or return to regular community activities), as well as health, social behaviour, and quality of life.

Clinician-reported CDEs are gathered with a focus on the time immediately after an injury. The CDEs reported include amnesia (before/after injury), loss of consciousness, alteration of consciousness, seizure within 48 hours, vomiting, Glasgow Coma Scale score, and CT scan, as well as mechanism of injury, use of protective equipment, and healthcare services accessed immediately after the injury.

\section{RESULTS}

The purpose of this paper was to present the recommended CDEs for TC. Future studies will present aggregate CDE data and results.

\section{DISCUSSION}

\section{Strengths of CDEs for Concussion Care}

The standardization of concussion care data across the province of Ontario will provide powerful information. CDEs can improve the efficiency of data collection for concussion care while decreasing strain on patients, who are frequently asked to recall information by different HCPs at different time points. CDEs can accompany the patient and be consistently monitored throughout their trajectory of care. The implementation of CDEs can improve the orientation of trainee clinicians by assisting them to more easily identify health conditions among patients for further investigation and advanced management. ${ }^{11}$ Furthermore, without a standardized and consistent approach to data collection for each patient, it is difficult to evaluate whether clinical interventions have been effective. Research-based initiatives using CDEs have been shown to help to advance medical treatments. ${ }^{3,12}$ CDEs allow for ease of evaluation of the impact of medical interventions, including individual patient progress, as well as allowing analyses of multi-site research studies at the local, provincial, national, and international levels.

For many clinical centres across the province, small-scale studies present challenges in terms of the length of time required to obtain a sufficient number of enrolled patients to allow for adequate power in statistical analyses. CDEs allow for sound statistical analyses of aggregate data for use in addressing individual clinic as well as larger population-level questions. ${ }^{11}$ A shared database will help to identify adverse outcomes common to concussion and the associated risk factors, thereby allowing for the development of improved clinical interventions to mitigate these risk factors. Standardization will facilitate highquality data harmonization by supporting meta-analysis of patient data $^{4}$ and could lay the foundation for the creation of a concussion registry for patients with PSs. The collection of CDEs will enable better characterization of patient trajectory in the years following concussion. Data sharing of standardized de-identified CDEs will provide a large provincial resource for advancing knowledge of short- and long-term outcomes of concussion. Collecting CDEs will shift research questions and move treatment evaluation toward a comparative effectiveness approach. ${ }^{3,4,12}$ This can help to improve Ontario's ability to address questions about the magnitude, as well as risk factors, protective factors, natural history, and patterns of recovery in concussion and to resolve service gaps to improve resource utilization.

A congruent shared database can establish a basis for comparison with other data sources. The sharing of data methodologies and associated tools, rather than summaries of interpretations of data collected by each individual HCP, can accelerate research progress by allowing independent, unbiased re-analysis of data, as well as re-aggregation, integration, and rigorous comparison with other datasets, tools, and methods. ${ }^{13}$ Implementing CDEs province-wide will help to better inform health policy and resource planning. The resulting clinical knowledge accrued from data analyses can be used to establish benchmarks for provincial standards of care.

\section{Limitations of CDEs for Concussion Care}

In Ontario, the development of data sharing agreements will require ongoing collaborative work. Steps to sustain data quality will be ongoing. To this end, transcription of paper-based questionnaires to electronic spreadsheets is performed by double entry of questionnaires to minimize data entry errors. At this time, staff and resources to support data collection and management are limited, and student volunteers have been one solution. The quality of patient responses in the self-reported questionnaire requires consideration. The "good old days bias" with selfreported patient data has been identified. ${ }^{34}$

Patient feedback on the implementation of CDEs was gathered. Patients expressed symptoms of fatigue when completing the paper-and-pencil questionnaires, likely related to the length of 
the instruments. Limiting the number of CDEs is a challenging but important consideration in an effort to minimize patient fatigue and maximize patient participation. Moving from paper-based to electronic data capture is a critical next step. The OCCS has planned a system of direct patient data entry into a secure patientfriendly and de-identified web-based system using REDCap. ${ }^{35}$ Utilizing a secure and private web-based data collection system, patients can take the time they need to enter their data at home. The electronic data capture system will have the capacity to construct a large dataset from smaller datasets across the province.

Some OCCS TC sites questioned the utility of certain CDEs and the exclusion of others. Selection and revision of CDEs will be considered a continuing process. ${ }^{4}$ In response and to address the evolving interests and priorities of CDEs, the OCCS established a process of biannual reviews of CDEs. It has also been recognized that selected data elements may be of relevance only to specific subpopulations, and as such require further study for supplemental data elements for Ontario. Examples include CDEs on stress and resilience. Experimental CDEs have been introduced to facilitate novel research inquiry. These include adverse childhood experiences, physical activity levels, pain assessment, and health service utilization. With the implementation of standardized data collection at OCCS sites, each TC site established a data steering committee. These committees regularly monitor and review data quality and provide a forum in which to present clinician and patient feedback for discussion, which is relayed back to the OCCS CDE subcommittee for discussion.

As the number of HCP settings implementing collection of CDEs increases, the possibility of a shared database for patients with concussion across Ontario is becoming a reality. Ongoing challenges to develop a large provincial aggregate electronic database include the integration of proprietary data capture systems and the implementation of resiliency (such as safety nets for a database $\mathrm{s}^{13}$ and individual health institutional review ethics board approval). The OCCS will require a sophisticated IT platform for electronic data capture, storage, and data use and sharing. A considerable amount of funding and resource personnel will be required to sustain a quality shared database.

\section{ConClusions}

The OCCS has taken a methodologically rigorous and collaborative approach to arrive at CDEs to standardize data in concussion care and research in Ontario. This phase-one CDE implementation focused on TC settings. In this phase, data collection has relied on patient self-report. Patients complete a questionnaire to describe demographics, physical environment, risk factors, protective factors, co-morbidities, and other social determinants of their health. Clinician-reported measures in phase one have been limited to focus on immediate post-injury factors. As the CDEs move into phase two, the OCCS may consider adding physical exam findings as well as MRI and/or x-ray findings. As the implementation of CDEs spreads, an abundance of high-quality data will be available to assist HCPs and researchers. These data will have the ability to be used to improve estimates on the magnitude of the problem of concussion, to characterize the experience of concussion by examining symptoms over time, and to assess service delivery. Further, it can be used to identify groups at high risk and to document the characteristics of the patients served and their health outcomes.

Standardized data on concussions will build a surveillance system for better understanding of concussion injuries in Ontario. Ongoing and future observational clinical studies enrolling patients with concussion can be linked across regions and across the province with standardized data. Multi-centre and international clinical research efforts can be facilitated using the internationally recognized CDEs. The results derived from the CDE concussion database will foster prevention strategies and establish priorities for research.

The OCCS invites new partners from across Ontario to join the collaborative network and to promote implementation and spread of CDEs throughout the patient care pathway. Dissemination of the CDEs to other centres of care continues through consultation and collaboration. Scalability and sustainability of CDEs will require human and financial resources. Work is underway to recommend CDEs for emergency departments and family practice clinicians. The CDEs for these care settings will need to match and flow into the pathway of CDEs recommended for TC. Other research has suggested that CDEs can be useful in triage tools to support clinical decisions for timely and appropriate referrals and for early access to specialty care for those patients in need. ${ }^{5}$

Standardized data collection using CDEs is a promising road map for system-wide improvement in concussion care. While no single measure can capture the progress of a patient after a concussion, the implementation of CDEs can help to shift Ontario toward internationally recognized standard data collection and in so doing yield a more comprehensive, evidence-based approach to care and support rigorous research. Without a common language to report and monitor concussion care, PSs may go unnoticed and undocumented, leading to an increased long-term burden of patient suffering with unnecessary healthcare costs. The ICF theoretical model provides a framework to describe CDEs with regard to functioning and disability in everyday activities. The use of the ICF model allows for ease of communication among HCPs and researchers from different disciplines. The OCCS is working collaboratively to enable the construction of a database to yield high-quality evidence to inform a "big-picture approach" to concussion care across Ontario. The spread of CDEs will help shift Ontario toward a stronger evidence-based approach to care. The implementation of CDEs aligns Ontario with the international movement toward standardized data that is currently being undertaken in the United States and Europe, thereby positioning the province to contribute significantly to reducing the burden of concussion.

\section{ACKNOWLEDGMENTS}

This project has been supported by the generous donations of Mr. Richard Currie, the CUMBA Foundation, and the Ontario Neurotrauma Foundation. We also thank the partners in OCCS, including The Ottawa Hospital, the Toronto Rehabilitation Institute, the Fowler Kennedy Sports Medicine Clinic, Holland Bloorview Hospital, and Lakehead University.

\section{Disclosures}

All the authors hereby declare that they have nothing to disclose. 


\section{Statement OF AUTHORShIP}

All authors are members of the OCCS Common Data Element Committee and have assisted in the identification and implementation of CDEs as well as in the review of this manuscript.

\section{REFERENCES}

1. Cassidy J, Carroll L, Peloso P, et al. Incidence, risk factors of mild traumatic brain injury: results of the WHO Collaborating Centre Task Force on Mild Traumatic Brain Injury. J Rehab Med. 2004: (43 Suppl):28-60.

2. Hicks R, Giacino J, Harrison-Felix C, Manley G, Valadka A, Wilde EA. Progress in developing common data elements for traumatic brain injury research: version two-the end of the beginning. J Neurotrauma. 2013;30(22):1852-61.

3. Editor. The changing landscape of traumatic brain injury research. Lancet Neurol. 2012;11(8):651.

4. Mass AI, Harrison-Felix CL, Menon D, et al. Standardizing data collection in traumatic brain injury. J Neurotrauma. 2011;28 (2): $177-87$

5. Silverburg ND, Gardner AJ, Brubacher JR, Panenka WJ, Li JJ, Iverson GL. Systematic review of multivariable prognostic models for mild traumatic brain injury. J Neurotrauma. 2015; 32(8):517-26

6. Bell JM, Taylor CA, Breiding MJ. The public health approach to TBI. J Head Trauma Rehabil. 2015;30(3):148-9.

7. Ontario Neurotrauma Foundation. Guidelines for Concussion/mTBI and Persistent Symptoms, 2nd ed. Toronto: Ontario Neurotrauma Foundation; 2013, Available at: http://onf.org/documents/guidelines-for-concussion-mtbi-persistent-symptoms-second-edition.

8. Langer L, Bayley MT, Levy C. Evaluating access to appropriate concussion care in Ontario. Arch Phys Med Rehabil. 2013;94(10): e38.

9. Hunt C, Zanetti K, Kirkham B, et al. Identification of Hidden Utilization Services and Costs in Adults Awaiting Tertiary Care Following Mild Traumatic Brain Injury in Toronto, Ontario, Canada. Toronto: Future Medicine; 2016, Available at: http://www. futuremedicine.com/doi/full/10.2217/cnc-2016-0009.

10. Ellis M, Ritchie L, Selci E, Chu S, McDonald PJ, Russell K. Googling concussion care: a critical appraisal of online concussion healthcare providers and practices in Canada. Clin $\mathrm{J}$ Sports Med. 2016;27(2):179-82.

11. Wilde EA, Whiteneck GG, Bogner J, et al. Recommendations for the use of common outcome measures in traumatic brain injury research. Arch Phys Med Rehabil. 2010;91(11):1650-60.

12. Wilkins SA, Shannon CN, Brown ST, et al. Establishment of a multidisciplinary concussion program: impact of standardization on patient care. J Neurosurg Pediatr. 2014;13(1):82-9.

13. Thompson HJ, Vavilala M, Rivara F. Common data elements and federal interagency traumatic brain injury research informatics system for TBI research. Annu Rev Nurs Res. 2015; 33:1-11.

14. National Institute of Neurologic Disorders and Stroke (NINDS). NINDS Common Data Elements. Bethesda, MD: NINDS; 2017, Available at http://www.commondataelements.ninds.nih.gov/ \#page= Default

15. McCrory P, Meeuwisse W, Aubry M, et al. Consensus statement on concussion in sport: the 4th international conference on concussion in sport held in Zurich, November 2012. Br J Sports Med. 2013;47(5):250-8

16. World Health Organization. International Classification of Functioning, Disability and Health (ICF). Geneva: World Health Organization; 2017, Available at http://www.who.int/ classifications/icf/en/.
17. Laxe S, Cieza A, Castano-Monsalve B. Rehabilitation of traumatic brain injury in the light of the ICF. NeuroRehabilitation. 2015;36(1):37-43.

18. Raggi A, Leonardi M, Covelli V, et al. The ICF as a framework to collect and interpret data on the extent and variety of disability in neurological conditions. NeuroRehabilitation. 2015;36(1): $17-22$.

19. Nguyen T, Fayed N, Gorter JW, MacDermid J. Enhancing interprofessional education and practice: development and implementation of a new graduate-level course using the international classification of functioning, disability and health. J Interprof Care. 2016;30(3):385-7.

20. Snyman S, Von Pressentin KB, Clarke M. International Classification of Functioning, Disability and Health: catalyst for interprofessional education and collaborative practice. J Interprof Care. 2015;29(4):313-9.

21. Haddon W. A logical framework for categorizing highway safety phenomena and activity. J Trauma. 1972;12(3):193-207.

22. Felitti VJ, Anda RF, Nordenberg D, et al. Relationship of childhood abuse and household dysfunction to many of the leading causes of death in adults: The Adverse Childhood Experiences (ACE) Study. Am J Prev Med. 1998;14(4):245-58.

23. Corrigan JD, Bogner J. Initial reliability and validity of the Ohio State University TBI Identification Method. J Head Trauma Rehabil. 2007;22(6):318-29.

24. Weyer Jamora C, Schroeder SC, Ruff RM. Pain and mild traumatic brain injury: the implications of pain severity on emotional and cognitive functioning. Brain Inj. 2013;27(10):1134-40.

25. Nasreddine ZS, Phillips NA, Bédirian V, et al. The Montreal Cognitive Assessment MoCA: a brief screening tool for mild cognitive impairment. J Am Geriatr Soc. 2005;53(4):695-9.

26. King NS, Crawford S, Wenden FJ, Moss NE, Wade DT. The Rivermead Post Concussion Symptoms Questionnaire: a measure of symptoms commonly experienced after head injury and its reliability. J Neurol. 1995;242(9):587-92.

27. Wiseman-Hakes C, Ouellet MC. Sleep and Concussion Questionnaire-Revised; 2016. Available at: https://www.researchgate. net/publication/304037738_Sleep_and_Concussion_QuestionnaireRevised.

28. Spitzer RL, Kroenke K, Williams JB, Löwe B. A brief measure for assessing generalized anxiety disorder: the GAD-7. Arch Intern Med. 2006;166(10):1092-7.

29. Kroenke K, Spitzer RL, Williams JB. The PHQ-9: validity of a brief depression severity measure. J Gen Intern Med. 2001;16 (9):606-13

30. Borgaro S, Gierok S, Caples H, Kwasnica C. Fatigue after brain injury: initial reliability study of the BNI Fatigue Scale. Brain Inj. 2004;18(7):685-90.

31. Whiteneck GG, Dijkers MP, Heinemann AW, et al. Development of the Participation Assessment with Recombined Tools-Objective for use after traumatic brain injury. Arch Phys Med Rehabil. 2011;92(4):542-51.

32. Steinbuechel NV, Wilson L, Gibbons $\mathrm{H}$, et al. QOLIBRI overall scale: a brief index of health-related quality of life after traumatic brain injury. Neurol Neurosurg Psychiatry. 2012;83 (11):1041-7.

33. Prins A, Ouimette P, Kimerling R, et al. The primary care PTSD screen (PC-PTSD): development and operating characteristics. Prim Care Psychiatry. 2003;9:9-14.

34. Iverson GL, Lange RT, Brooks BL, Rennison VLA. "Good old days" bias following mild traumatic brain injury. Clin Neuropsychol. 2010;24(1):17-37.

35. Harris PA, Taylor R, Thielke R, Payne J, Gonzalez N, Conde JG. Research Electronic Data Capture (REDCap): a metadata-driven methodology and workflow process for providing translational research informatics support. J Biomed Inform. 2009;42(2): $377-81$. 